\title{
Linear Distance: A Multi-Tiered Methodology in the Acquisition of Gender Agreement
}

\author{
Pierre-Luc Paquet \\ University of Guanajuato \\ Faculty of Social Sciences and Humanities
}

Received 31 March 2018 • Revised 7 May 2018 • Accepted 12 May 2018

\begin{abstract}
This research investigates the influence of L1 properties and proficiency level on the acquisition of gender agreement addressing linear distance as a possible cause of errors. French and Englishspeaking learners of Spanish participated in the study. Subjects were divided into four different groups considering their L1 (French and English) and their proficiency level (intermediate and advanced). Subjects completed three different tasks: an untimed grammaticality judgment task (UGJT), an elicited oral imitation test (EOI), and an eye-tracking experiment. As for linear distance, each experimental item was distributed across three distance conditions: distance number 1 corresponds to an adjacent adjective pattern, distance number 2 separates the adjective using a copula, and distance number 3 included between three and four words interceding before the copula. Our results show no linear distance effect for either the explicit task or the implicit task.
\end{abstract}

Keywords: grammatical gender, adjective agreement, L2 Spanish, proficiency level, eye-tracking, linear distance.

\section{Introduction}

The acquisition of agreement in a second language, such as tense, gender and number, is often problematic, even for learners with an advanced proficiency level (Tokowizc \& MacWhinney, 2005; Bond, Gabriele, Fiorentino \& Bañón, 2011; Bañón, Fiorentino \& Gabriele, 2014; among others). Although there have been several studies trying to explain the sources of difficulty in the acquisition of agreement, a consensus has not yet been reached. The difficulties with agreement affect not only comprehension but also production (Paquet, 2018). This is why it remains a methodological challenge to identify the different sources of difficulty and that there is a need for a multi-tiered methodology to best investigate the acquisition of agreement in a second language. Few studies have addressed the variables that might cause agreement errors, such as the linear distance between the agreeing elements. The studies that have examined this issue are Keating (2009), Lichtman (2010), Foote (2011) and Lago \& Felser (2018), among others.

Consequently, this study examines the influence of L1 properties and proficiency level on the acquisition of gender agreement addressing linear distance as a possible cause of errors. More specifically, we will present the results of an offline untimed grammaticality judgment task, an elicited oral imitation test and an online eye-tracking experiment examining the effect of

(C) Authors. Terms and conditions of Creative Commons Attribution 4.0 International (CC BY 4.0) apply. Correspondence: Pierre-Luc Paquet, Calzada de Guadalupe s/n; Zona Centro; Guanajuato, Gto., C.P. 3600o, MEXICO. E-mail: pl.paquet@ugto.mx. 
proficiency and L1 properties on the processing of short- and long-distance gender agreement between the controller noun and its modifying adjective in Spanish. Using these experiments also allow us to observe both learners explicit and implicit knowledge as well as their receptive and expressive competencies. In the next sections, before we move to the current research project, we first present the Spanish gender agreement system and the possible influence of L1 properties on its acquisition. Then, we review research studies which were examining the effect of linear distance as a possible source of errors. Finally, we explain the difference between explicit and implicit knowledge and how these types of knowledge are measured.

- To observe second language processing, a multi-tiered methodology should be used.

- Linear distance effect does not reveal itself as a potential source of errors.

- L1 properties and proficiency play deterministic roles in the acquisition of gender.

\subsection{Acquisition of gender agreement}

According to Corbett (1991), the existence of gender is revealed by morpho-syntactic agreement. In Spanish, the target language of the present study, adjectives grammatically agree with the nouns which they refer to (Real Academia Española, 2010; Bosque \& Demonte, 1999). In many cases, morpho-phonological properties of the noun can provide a cue to its gender, with nouns ending in $-\mathrm{o}$ (e.g. bolso "handbag") for masculine class and those ending in -a (e.g. mochila "backpack") for feminine class, although there are exceptions to these rules (see Montrul, Foote \& Perpiñán, 2008). As for the French gender agreement system, adjectives grammatically agree with nouns as in Spanish, in that they both work comparably. Compared to gendered languages such as Spanish and French, English does not mark grammatical gender on either nouns or adjectives (e.g. brown handbag). Even though gender agreement seems to be regulated by a well-established system, many studies have investigated the acquisition of this morpho-syntactic aspect without reaching a consensus.

As for studies using online receptive tasks, such as eye-tracking and event-related brain potentials, results demonstrated that sensitivity to agreement discord is associated with the presence of gender marking in the learners' L1 properties (e.g. Bond et al., 2011; Foucart \& FrenckMestre, 2011), as well as of learners' proficiency level in the L2 (Keating, 2009; Sagarra \& Herschenhohn, 2011, 2013; Gabriele, Fiorentino \& Bañón, 2013). Likewise, according to Morales, Dussias, Valdés Kroff, Gerfen \& Bajo (2015), learners whose L1 encodes grammatical gender can come to use gender marking with a high degree of accuracy at intermediate proficiency levels. To the contrary, some studies indicate that even highly advanced L2 learners who speak a genderless L1 still struggle with gender agreement on determiners, even for highly familiar L2 nouns (LewWilliams \& Fernald, 2010; Grüter, Lew-Williams \& Fernald, 2012). In other words, the presence of a gender system in the learners' L1 presents itself as being beneficial in the acquisition of such a feature. It would also appear that gender agreement is a feature acquired later in the acquisition process (Foucart \& Frenck-Mestre, 2011; Judy et al., 2008; Montrul, de la Fuente, Davidson \& Foote, 2013; Paquet, 2018).

A previous research study sought to explore the influence of L1 properties and proficiency level on the acquisition of gender agreement (Paquet, 2018). The author suggested that both L1 properties and proficiency level, taken together, were affecting acquisition, as the advanced French-speaking learners of Spanish were the only group showing sensitivity to gender discord. Consequently, a more in-depth observation of these variables is needed addressing linear distance as a possible source of errors. 


\subsection{Linear distance as a source of agreement errors}

One of the factors that seems to affect the acquisition process of gender agreement is syntactic or linear distance. The former refers to the number of phrases separating the controller noun and its modifying adjective whereas the latter refers to the number of words (Keating, 2009; Lichtman, 2010; Foucart \& Frenck-Mestre, 2011). Agreement elements can be located close to each other, such as determiners or farther apart, such as noun-adjective agreement. Only few studies have examined linear distance as a possible source of errors in this area. The following briefly summarize the results from these studies considering their methodological design.

Keating (2009) used an online eye-tracking experiment to observe whether gender agreement errors between nouns and adjectives were detected differently by L2 learners and native speakers, considering the existing distance between the controller noun and its modifying adjective. The results from this study demonstrated that native speakers were sensitive to gender discord, whereas English-speaking L2 learners were not, except for the advanced group who were able to detect gender discord when nouns and adjectives were adjacent. In other words, advanced L2 learners were sensitive to gender discord, but sensitivity diminished as distance level increased.

A research study, conducted by Lichtman (2010), contradicted Keating's (2009) conclusions and indicated that L2 learners were able to overcome linear distance processing difficulty as proficiency increased (Lichtman, 2010). This study observed the effect of linear distance on the acquisition of the Spanish gender agreement system by means of two offline tasks, namely, a grammaticality judgment and a forced-choice task. Results demonstrated that the development of gender agreement followed a constant progression which was not affected by the presence of linear distance between the controller noun and its adjective.

Another study conducted by Foote (2011) revealed similar results. The author examined number and gender agreement from English speakers' learners of Spanish by means of two online self-paced reading tasks. These results suggested that Spanish native speakers and English-speaking learners were both sensitive to agreement violation. However, most significant differences in reading time were associated with situations where nouns and adjectives were adjacent. This suggests that, in accordance with Keating (2009), sensitivity to gender errors diminished as distance level increased.

In a study, Foucart and Frenck-Mestre (2011) compared the performance of French native speakers and German-speaking learners of French by means of an event-related brain potential experiment. They observed that processing of gender agreement is affected by the structural similarities between L1 and L2. However, regarding the distance effect between the agreeing elements, results demonstrated that sensitivity to gender discord was only existent in the short-distance condition, more specifically agreement between the determiner and the noun. These results are consistent with those of Keating (2009) and Foote (2011).

Recent research has explored the issue of distance by means of various tasks, which are divided between offline and online. For instance, Sagarra and Herschensohn (2010) conducted a study using an online self-paced reading task and an offline grammaticality judgment task to explore the acquisition of gender agreement and the influence of short- and long-distance conditions between the agreeing elements. Results from the online task showed that intermediate learners of Spanish were sensitive to gender discord in the short-distance condition. Regarding the offline task, results demonstrated that all participants were able to complete such a task with a high degree of accuracy. This being said, it is important to consider using a multi-tiered methodology to best investigate this issue.

As can be noted from the previously mentioned research studies, most have used either offline or online tasks to examine the influence of distance on the acquisition of gender agreement. Offline tasks are defined as those in which data is collected after processing has 
occurred and most of them are considered as measures of learners' explicit knowledge. In contrast, online tasks are those in which data is collected while processing is happening and measure learners' implicit knowledge. Most studies using online tasks demonstrated that learners were more sensitive to agreement discord when the agreeing elements were adjacent (Keating, 2009; Sagarra \& Herschensohn, 2010; Foote, 2011; Frenck-Mestre, 2011). As for the offline tasks, results showed that distance should not be considered as a permanent source of errors since learners seemed to exhibit a constant progression (Lichtman, 2010; Sagarra \& Herschensohn, 2010). In other words, offline tasks are understood as a measure of explicit knowledge, whereas online tasks are recognized as a measure of implicit knowledge. The current study takes into consideration Sagarra and Herschensohn's (2010) recommendation and therefore included three different measures to explore distance as a potential source of errors while examining learners' explicit and implicit knowledge of gender agreement.

\subsection{Objectives and research questions}

This experiment was designed to investigate Spanish learners' knowledge of adjective agreement as linear distance between the adjective and the noun increases. In addition to looking for evidence of a possible 'distance effect', the study considers the influence of the learners' L1 properties (French and English speakers) and proficiency level (intermediate and advanced) in the ability of Spanish students to apply their knowledge of adjective agreement. The research questions are as follows:

(1) Do Spanish L2 learners detect incorrect adjective agreement more accurately when the adjective is closer to the noun, in linear distance?

The prediction for the first research question, whether L2 learners detect gender agreement discord more accurately when the agreeing elements are adjacent, is that L2 learners will show less sensitivity to agreement discord as distance increases. This prediction follows Keating's (2009), Sagarra and Herschensohn's (2010), and Foote's (2011) studies, which all suggest distance effect as being a source of difficulty in L2 processing.

(2) Are there task effects for acquisition of agreement, such that learners perform better on an explicit task rather than an implicit task, in terms of distance level?

The prediction for the second research question, whether L2 learners perform better on the explicit task than the implicit tasks (2) in regards to distance level, is that L2 learners will be more accurate in the offline task, measuring their explicit knowledge, than in the online tasks. The fact that it is well established that explicit and implicit knowledge are not accessed the same way leads us to suggest that there will be a difference in the impact of each distance condition. This prediction follows Sagarra and Herschensohn's (2010) study, whose results demonstrated that learners were able to complete the explicit task with a high level of accuracy.

(3) Do L1 properties and proficiency level influence the detection of errors and the learners' performance as distance increases?

The third research question focuses on examining to what extent learners' L1 properties and proficiency level influence the detection of errors and the learners' performance as distance increases. Since most studies (e.g. Keating, 2009; Foucart \& Frenck-Mestre, 2011; Sagarra \& Herschensohn, 2010; Foote, 2011) suggest the influence of L1 properties and proficiency level, we predict that the same observation will be made when it comes to distance level as a source of errors. 


\section{Method}

A between-subjects design was employed to explore how linear distance affects the development of explicit and implicit knowledge of grammatical gender agreement in L2 Spanish. Explicit knowledge was measured through an untimed grammaticality judgment task (UGJT), whereas implicit knowledge was assessed through both an eye-tracking experiment and an elicited oral imitation test (EOI).

\subsection{Participants}

Twenty-three English and twenty French speakers' learners of Spanish participated in the study. They were first asked to complete a placement test in other to classify them into one of the four groups: English-intermediate $(n=11)$, English-advanced $(n=12)$, French-intermediate $(n=10)$ and French-advanced $(n=10)$. Participants who had learned and/or were previously exposed to any other L2s with grammatical gender were excluded from the study. Given the linguistic context of Canada, English-speaking Canadians were not considered for participation because of their probable active or passive knowledge of the French language. For that reason, the English-speaking subjects were all undergraduate students at a college in the northeast of the United States. The English participants included 10 males and 13 females. As for the Frenchspeaking subjects, they were all enrolled in a postsecondary education program at different institutions in the province of Quebec in Canada. The French participants included 4 males and 16 females. Finally, for their data to be included in the results, all participants needed to complete all tasks, which were divided into two different sessions. Table 1 specifically illustrates the age range, number of Spanish courses completed and length of immersion in a Spanish-speaking country.

Table 1. Background information for the L2 learners of Spanish

\begin{tabular}{|c|c|c|c|}
\hline Group & Age range & $\begin{array}{l}\text { Number of Spanish } \\
\text { courses completed }\end{array}$ & $\begin{array}{l}\text { Length of immersior } \\
\text { in a Hispanic } \\
\text { country }\end{array}$ \\
\hline \multicolumn{4}{|c|}{ English intermediate $(n=11)$} \\
\hline Mean & 18.64 & 3.36 & 0.55 \\
\hline Range & $18-20$ & $0-4$ & $0-6$ \\
\hline$S D$ & 0.67 & 1.21 & 1.81 \\
\hline \multicolumn{4}{|c|}{ English advanced $(n=12)$} \\
\hline Mean & 20.08 & 4.17 & 2.75 \\
\hline Range & $18-22$ & $3-7$ & $0-12$ \\
\hline$S D$ & 1.16 & 1.03 & 4.56 \\
\hline \multicolumn{4}{|c|}{ French intermediate $(n=10)$} \\
\hline Mean & 32.6 & 0.9 & 0.70 \\
\hline Range & $17-64$ & $0-5$ & $0-5$ \\
\hline$S D$ & 15.73 & 1.91 & 1.64 \\
\hline \multicolumn{4}{|c|}{ French advanced $(n=10)$} \\
\hline Mean & 40.00 & 0.90 & 15.4 \\
\hline Range & $29-71$ & $0-4$ & $0-84$ \\
\hline$S D$ & 15.92 & 1.52 & 25.78 \\
\hline
\end{tabular}

\subsection{Materials and design}

The materials for the three tasks consisted of 24 sentences involving noun-adjective gender agreement, half of which were grammatical (i.e. the noun and modifying adjective agreed in gender) and half were ungrammatical (i.e. the noun and modifying adjective did not agree in gender). Noun gender (masculine vs. feminine) was matched across conditions, whereas linear 
distance between the noun and its agreeing adjective was organized into three levels (see Table 2). The experimental items followed the same syntactic structure in all three experiments to complete. In each task, the 24 experimental items were mixed with 24 filler sentences that tested other aspects of grammar (tense, number agreement and verb conjugation).

The nouns and the adjectives used in this study were rigorously selected. First, all experimental nouns and adjectives ended in the suffixes commonly associated with gender ( $-\mathrm{o}$ for masculine and $-\mathrm{a}$ for feminine). This was done to ensure that the emphasis was on gender agreement, not assignment. Errors in gender agreement are more salient when gender is marked morphologically on nouns and adjectives. Second, in order to eliminate confounding effects, we only used grammatical gender leaving semantic gender aside. Third, to ensure that the results were not influenced by unfamiliar words, all nouns $(n=55)$ and adjectives $(n=47)$ were selected from the benchmarks for beginners (A1-A2) of the Plan Curricular del Instituto Cervantes (Instituto Cervantes, 2006). As shown in Table 2, we controlled for terminal morphology, type of gender and word familiarity. However, creating 24 sentences per experiment constrained us to recycle experimental nouns and adjectives.

Table 2. Experimental items

\begin{tabular}{|c|c|}
\hline Examples of experimental items & Location of adjecti \\
\hline $\begin{array}{l}\text { 1a) La fruta preferida de mi tía Gabriela es la naranja. } \\
\text { 'My aunt Gabriela's favorite fruit is the orange.' } \\
\text { 1b) El Quijote es un libro *famosa de la literatura española. } \\
\text { 'Don Quixote is a famous novel of Spanish literature.' }\end{array}$ & $\begin{array}{c}\text { Adjacent } \\
\text { (attributive) }\end{array}$ \\
\hline $\begin{array}{l}\text { 2a) El verano es hermoso con flores, montañas y sol } \\
\text { 'The summer is wonderful with its flowers, mountains and sun.' } \\
\text { 2b) En los aeropuertos, un refresco es *cara para los viajeros. } \\
\text { 'At the airport, a soft-drink is expensive for travellers' }\end{array}$ & $\begin{array}{c}+1 \text { word } \\
\text { (predicative) }\end{array}$ \\
\hline $\begin{array}{l}\text { 3a) La comida de la cocinera está preparada con poca sal. } \\
\text { 'The cook's food is prepared with little salt' } \\
\text { 3b) El empleo de mi padre es *aburrida y muy dificil. } \\
\text { 'My father's job is boring and very difficult.' }\end{array}$ & $\begin{array}{l}+4-5 \text { words } \\
\text { (predicative) }\end{array}$ \\
\hline
\end{tabular}

Grammaticality and gender categories allowed us to examine the influence of distance effect on the acquisition of the Spanish gender agreement system. All of the sentences were eight to twelve words long, so that processing demands would not cause longer sentences to be rejected or misunderstood.

\subsection{Procedure}

Participants first completed a screening test (placement test) in order to classify them in the right group. Afterwards, they performed an elicited oral imitation test (EOI) and an untimed grammaticality judgment task (UGJT). Finally, subjects completed in the eye-tracking experiment. As Sagarra \& Herschensohn (2011) suggested, we should have gone from the most implicit to the most explicit measure so that the latter does not bias the implicit processes of the former. Because of technical difficulties and availability of the eye-tracking device, we were unable to replicate this suggestion. However, we separated the completion of the UGJT and the EOI from the eye-tracking experiment by two to three weeks, which we believe was sufficient to control the learners' awareness of the focus of the study. For the sake of clarity, the following description 
illustrates the continuum from explicit to implicit measures, namely, the UGJT followed by the EOI and the eye-tracking.

\subsubsection{Untimed grammaticality judgment}

The UGJT was designed to investigate learners' explicit knowledge of the Spanish gender agreement system through a receptive offline task. Since the UGJT required learners to focus on form and was not time constrained, it is considered a measure of explicit knowledge (Godfroid et al., 2015; Vafaee, Suzuki \& Kachisnke, 2017). In this experiment, participants read Spanish sentences silently on a computer screen, then decided whether each sentence was correct or incorrect and finally, if judged incorrect, indicated the location of the error. Subjects were allotted one point for identifying grammatical sentences as correct or ungrammatical ones as incorrect including identifying the error.

\subsubsection{Elicited oral imitation}

The EOI was designed to investigate learners' implicit knowledge of the Spanish gender agreement system within a semi-controlled expressive task. To date, this experiment is considered to be one of the most reliable tasks to measure implicit/intuitive L2 knowledge (Erlam, 2006; Zhang, 2015; among others). The EOI required participants to listen to a sentence in Spanish, to answer a yes or no comprehension question, which served as distraction, and then to reconstruct the sentence in the best Spanish possible. Each experimental item included a nounadjective gender agreement. The sentences used were organized based on three levels of distance crossed with two levels of grammaticality (Table 2). The EOI is reconstructive in nature and not rote repetition. Thus, we expected speakers who had internalized implicit knowledge of the target structure to spontaneously correct ungrammatical items, and so whether or not the distance between the noun and the adjective increases. One point was allotted when the noun-adjective agreement was well reconstructed and no point when reconstructed otherwise.

\subsubsection{Eye-tracking experiment}

Based widely on the recommendations of Keating (2009) and those of Roberts \& Siyanova-Chanturia (2013), the eye-tracking experiment was designed to investigate learners' implicit knowledge of the Spanish gender agreement system and the noun-adjective distance effect by means of an online receptive task. While reading, participants' eye movements were recorded with an EyeTechSensor tracking device designed by PerTech. Viewing was binocular, with eye movement recorded from the right eye. The apparatus was interfaced with a PC that controlled stimulus display and data storage. The sentences were presented individually on a 17-inch monitor. Sentences appeared in a single line in black against a light gray background using normal uppercase and lowercase letters.

Before each Spanish sentence, subjects were asked to fix a target that occupied the position of the sentence initial character. They were instructed to look at the fixation target while pressing the 'Advance' button to display the sentence. Participants were asked to read the Spanish sentences for meaning and to indicate whether the subsequent sentence (written in the subjects' L1) expressed the same general idea as the Spanish sentence by pressing YES or NO. This check for meaning served as a distractor from the possible ungrammaticality of the target item.

Although eye movements were recorded on every word in each sentence, analyses were limited to data obtained from three different measures: Total reading time and time allotted to the regions of interest (ROI) 'adjective' (in milliseconds), and the regressions to the controller noun 
(in percentage of probability). This study examined if there were differences in the data regarding the learners' reading of the grammatical and the ungrammatical sentences.

For comparability purposes, the EOI, the UGJT and the eye-tracking experiment contained the same number and type of sentences, but the content and noun-adjective combinations were different to avoid possible practice effects that would increase sensitivity to gender agreement violations.

\section{Results}

This section presents the learners' performance on noun-adjective agreement in Spanish. As mentioned previously, data from this set of experiments allowed us to examine learners' explicit knowledge (UGJT) as well as implicit knowledge (EOI and eye-tracking) of the target feature.

\subsection{Experiment 1: Untimed grammaticality judgment task}

The UGJT was aimed at examining the influence that linear distance has on the acquisition of explicit knowledge by means of an offline receptive task. In order to make sure that we observed learners' explicit knowledge, we did not impose any time constraint and made sure that learners' attention was directed towards the linguistic forms.

As shown in Table 3, when isolating each distance condition, the data showed no significant differences as the distance between the noun and its modifying adjective increased. All participants completed the UGJT with a high level of accuracy. As for the between subjects' variables, it seems that the English-speaking learners of Spanish were less efficient at judging the ungrammatical than the grammatical items. The same observation manifested itself in terms of proficiency level where the intermediate learners struggled more with the ungrammatical items. However, when we look at the distribution of the data, we come to realize that distance does not affect the learners' responses, and therefore cannot be considered as a source of errors, since they reached similar results in each distance condition.

Table 3. UGJT results (Standard deviation appears in parentheses)

\begin{tabular}{|c|c|c|c|c|c|c|c|}
\hline \multirow{3}{*}{ Groups } & \multirow{3}{*}{$\mathrm{N}$} & \multicolumn{6}{|c|}{ Distance level } \\
\hline & & \multicolumn{2}{|c|}{ Distance $\mathrm{n} \cdot 1$} & \multicolumn{2}{|c|}{ Distance $n \cdot 2$} & \multicolumn{2}{|c|}{ Distance $\mathrm{n} \cdot 3$} \\
\hline & & OG & OGI & OG & OGI & OG & OGI \\
\hline \multicolumn{8}{|l|}{ Proficiency level } \\
\hline Intermediate & 21 & $\begin{array}{c}94.05 \\
(.11)\end{array}$ & $\begin{array}{c}72.62 \\
(.36)\end{array}$ & $\begin{array}{c}94.05 \\
(.18)\end{array}$ & $\begin{array}{l}73.81 \\
(.29)\end{array}$ & $\begin{array}{c}92.86 \\
(.23)\end{array}$ & $\begin{array}{c}77.38 \\
(.29)\end{array}$ \\
\hline Advanced & 22 & $\begin{array}{c}96.59 \\
(.09)\end{array}$ & $\begin{array}{l}87.50 \\
(.20)\end{array}$ & $\begin{array}{c}98.86 \\
(.05)\end{array}$ & $\begin{array}{c}85.23 \\
(.24)\end{array}$ & $\begin{array}{c}98.86 \\
(.05)\end{array}$ & $\begin{array}{c}87.50 \\
(.21)\end{array}$ \\
\hline \multicolumn{8}{|l|}{ L1 properties } \\
\hline English speakers & 23 & $\begin{array}{l}95.65 \\
(.10)\end{array}$ & $\begin{array}{l}71.74 \\
(.36)\end{array}$ & $\begin{array}{c}97.83 \\
(.07)\end{array}$ & $\begin{array}{c}68.48 \\
(.31)\end{array}$ & $\begin{array}{c}97.83 \\
(.07)\end{array}$ & $\begin{array}{c}76.09 \\
(.30)\end{array}$ \\
\hline French speakers & 20 & $\begin{array}{c}95.00 \\
(.10)\end{array}$ & $\begin{array}{c}90.00 \\
(.15)\end{array}$ & $\begin{array}{c}95.00 \\
(.17)\end{array}$ & $\begin{array}{c}92.50 \\
(.12)\end{array}$ & $\begin{array}{c}93.75 \\
(.23)\end{array}$ & $\begin{array}{c}90.00 \\
(.19)\end{array}$ \\
\hline
\end{tabular}

With regard to explicit knowledge, assessed through the UGJT, results demonstrated that all participants have the ability to accurately judge the grammaticality of the Spanish nounadjective agreement, even though there was a difference regarding item grammaticality. As for distance level, participants did not appear to be affected as the distance between the agreeing elements increased. Consequently, it seems that, when providing learners with time and focus on the linguistic features, learners demonstrated having explicit knowledge of gender agreement. 


\subsection{Experiment 2: Elicited oral imitation test}

This expressive task was conducted in order to investigate learners' implicit knowledge of the Spanish gender agreement system. Moreover, this second experiment aimed at examining whether linear distance presents itself as a possible source of errors when it comes to reconstructing sentences in Spanish.

Before we take a look at the analysis for the between-subject variables, it is important to mention that the item variable 'distance' revealed itself as significant with a level of significance below 0.05 of $\rho=.0003$. Unexpectedly, this significant difference does not seem to appear because of linear distance effect. As shown in Table 4, participants were more accurate at reconstructing items from the short-distance and the long-distance conditions than from the distance level number 2 where the noun and the adjective were separated by a copula. This could be due to task effect or to the possibility that syntactic distance influences more than linear distance.

As for the influence of L1 properties and proficiency level, they would appear to have a certain impact in reconstructing noun-adjective gender adequately. We also found a significant interaction between distance level and proficiency, with a level of significance below 0.05 of $\rho=.0242$. This interaction suggested that intermediate learners, more specifically the English intermediate, were less likely to reconstruct items when the noun and the adjective were separated by a copula (distance level number 2) than in the other distance conditions.

Table 4. EOI results (Standard deviation appears in parentheses)

\begin{tabular}{|c|c|c|c|c|c|c|c|}
\hline \multirow{3}{*}{ Groups } & \multirow{3}{*}{$\mathrm{N}$} & \multicolumn{6}{|c|}{ Distance level } \\
\hline & & \multicolumn{2}{|c|}{ Distance $n \cdot 1$} & \multicolumn{2}{|c|}{ Distance $\mathrm{n} \cdot 2$} & \multicolumn{2}{|c|}{ Distance $n \cdot 3$} \\
\hline & & OG & OGI & OG & OGI & OG & OGI \\
\hline \multicolumn{8}{|l|}{ Proficiency level } \\
\hline Intermediate & 21 & $\begin{array}{c}66.67 \\
(.23)\end{array}$ & $\begin{array}{c}47.62 \\
(.33)\end{array}$ & $\begin{array}{c}60.71 \\
(.26)\end{array}$ & $\begin{array}{c}17.86 \\
(.25)\end{array}$ & $\begin{array}{c}67.86 \\
(.23)\end{array}$ & $\begin{array}{c}55.95 \\
(.27)\end{array}$ \\
\hline Advanced & 22 & $\begin{array}{c}75.00 \\
(.18)\end{array}$ & $\begin{array}{c}65.48 \\
(.22)\end{array}$ & $\begin{array}{c}75.00 \\
(.25)\end{array}$ & $\begin{array}{c}52.38 \\
(.33)\end{array}$ & $\begin{array}{c}71.43 \\
(.21)\end{array}$ & $\begin{array}{c}59.52 \\
(.34)\end{array}$ \\
\hline \multicolumn{8}{|l|}{ L1 properties } \\
\hline English speakers & 23 & $\begin{array}{c}66.30 \\
(.22)\end{array}$ & $\begin{array}{l}52.17 \\
(.24)\end{array}$ & $\begin{array}{c}61.96 \\
(.25)\end{array}$ & $\begin{array}{c}28.26 \\
(.32)\end{array}$ & $\begin{array}{c}69.57 \\
(.23)\end{array}$ & $\begin{array}{c}48.91 \\
(.29)\end{array}$ \\
\hline French speakers & 20 & $\begin{array}{c}76.32 \\
(.18)\end{array}$ & $\begin{array}{l}61.84 \\
(.34)\end{array}$ & $\begin{array}{c}75.00 \\
(.26)\end{array}$ & $\begin{array}{c}43.42 \\
(.34)\end{array}$ & $\begin{array}{c}69.74 \\
(.21)\end{array}$ & $\begin{array}{c}68.42 \\
(.30)\end{array}$ \\
\hline
\end{tabular}

Regarding the acquisition of implicit knowledge within a semi-controlled expressive task, it is important to mention, as Erlam (2006) stated, the fact that all learners were able to reconstruct some of the ungrammatical sentences in each distance condition shows that they do have some implicit knowledge of Spanish gender agreement. As for distance effect as a possible source of errors in the acquisition of implicit knowledge, results indicated that the real problem might arise from syntactic instead of linear distance. However, after investigating discrete items, we believe these results to be more indicative of task effect than of syntactic distance.

\subsection{Experiment 3: Eye-tracking experiment}

This task was conducted to investigate learners' sensitivity to gender agreement discord within an online receptive reading experiment across three different distance levels. This section will enumerate data from this experiment, considering three different measures: total reading time, time allotted to the region of interest (ROI) "adjective" and finally, regression to the 
controller noun. Before we start analyzing the results, it should be pointed out that $37 \%$ of the data from the eye-tracking were excluded from the analysis due to technical difficulties.

In the eye-tracking experiment, the exploration of the potential distance effect on learners' implicit knowledge only comes to light bearing in mind the learners who demonstrated sensitivity to gender discord. Therefore, as far as the between-subjects variables are concerned, the only group who demonstrated such a tendency was the French advanced L2 learners of Spanish. Neither of the other groups, intermediates and English advanced, showed sensitivity to gender discord. For this reason, the following description only includes the results from French advanced learners of Spanish.

Before examining linear distance effect, it is important to mention that the item variable "grammaticality" is significant across all three measures, namely total reading time ( $\rho=.0003)$, reading time in ROI "adjective" ( $\rho<$.0001) and regression to controller noun ( $\rho=.0032$ ). The above results strongly suggest that the French advanced learners of Spanish are sensitive to gender discord, which runs counter to previous research on this issue.

Now that we have established that grammaticality is significant across all three measures, we looked at the possible interaction between grammaticality and distance levels. Statistical analysis did not present any significant interaction between these two, which refutes linear distance as a potential source of errors. As shown in Table 5, it seems that French advanced learners of Spanish process the grammatical sentences differently from the ungrammatical ones.

Table 5. Eye-tracking experiment - French advanced learners of Spanish

\begin{tabular}{|c|c|c|c|c|c|c|c|c|c|c|}
\hline \multirow{3}{*}{ Groups } & \multirow{3}{*}{$\mathrm{N}$} & \multicolumn{9}{|c|}{ Distance levels } \\
\hline & & \multicolumn{3}{|c|}{ Distance $n \cdot 1$} & \multicolumn{3}{|c|}{ Distance $n \cdot 2$} & \multicolumn{3}{|c|}{ Distance $n \cdot 3$} \\
\hline & & $\mathrm{OG}$ & OGI & Diff. & $\mathrm{OG}$ & OGI & Diff. & $\mathrm{OG}$ & OGI & Diff. \\
\hline $\begin{array}{c}\text { Total Reading Time } \\
\text { (s.) }\end{array}$ & 9 & 4.84 & 5.89 & 1.05 & 4.90 & 5.91 & 1.01 & 4.46 & 5.65 & 1.19 \\
\hline $\begin{array}{l}\text { Reading Time ROI } \\
\text { 'adjective' (s.) }\end{array}$ & 9 & 0.52 & 0.85 & 0.33 & 0.52 & 0.69 & 0.17 & 0.50 & 0.74 & 0.24 \\
\hline $\begin{array}{c}\text { Regression to } \\
\text { controller noun }(\%)\end{array}$ & 9 & 23.2 & 42.2 & 19.0 & 18.3 & 36.4 & 18.1 & 17.2 & 43.2 & 26.0 \\
\hline
\end{tabular}

Regarding the acquisition of implicit knowledge within an online receptive task, we should acknowledge the importance of examining distance effect in interaction with grammaticality. Despite the lack of significant results for the intermediate and the English advanced groups, it is not to say that these two groups are not engaged in the process of acquiring implicit knowledge of gender agreement. To the contrary, results demonstrated that the French advanced learners of Spanish have implicit knowledge of this feature, which strongly suggest an influence of L1 properties in combination with their level of proficiency.

\section{Discussion}

In all of the experiments included in this research, noun-adjective gender agreement took three possible variations based on linear distance. In our context, distance number 1 corresponds to an adjacent adjective pattern, distance number 2 separates the adjective from the controller noun using a copula, and distance number 3 is similar to distance number 2 except it included between three and four words interceding before the copula. Before we revisit the 
research questions of the present study, a brief summary of the results from our three experiments will be provided.

When it comes to the way learners were influenced by linear distance, the results gathered in the UGJT do not show any difference in the manner in which they process each distance level. However, as we examined distance level in the elicited oral imitation test, we can observe that the intermediate learners struggle more at reconstructing sentences when the adjective is separated from the controller noun by a copula (distance number 2). A further probe of these results revealed that learners had more difficulty with the ungrammatical sentences of distance number 2 than of distances number 1 and 3. After investigating distance number 2 discrete items, the combination of task instructions and semantics at the sentence level would have prevented learners from incorporating the given noun-adjective arrangements. Regarding the observation collected in the eye-tracking experiment, the only group presenting sensitivity to gender discord was the advanced French-speaking learners. Consequently, this was the only group that could shed light on the question of the influence of distance level. After examining the results, the findings did not appear to demonstrate any linear distance effect in the manner in which these learners read and processed gender agreement. In the research conducted by Keating (2009), advanced English-speaking learners demonstrated sensitivity to gender discord when the controller noun and its adjective were in the same phrase. Our results did not expose the same observation. Possible explanations could be either one of the influence of L1 properties or the fact that the advanced French L1 speakers in this study were more proficient than the ones in Keating's studies. However, the data collected in the present study cannot account for either of these explanations.

The resulting prediction of the first research question, which sought to observe learners' ability to detect incorrect adjective agreement as distance increases, was not substantiated. Based on previous studies, such as Keating (2009), Sagarra and Herschensohn (2010), and Foote (2011), we should have observed a downward trend as of the shortest-distance condition. Contrarily, our results from all three tasks did not indicate any differences between conditions, which suggest no linear distance effect.

Recall that the second research question explored whether learners perform better on an explicit task rather than an implicit task, in terms of distance level. The subsequent prediction was that L2 learners would be more accurate in the explicit task that in the implicit task, as Sagarra and Herschensohn (2010) stated. Generally speaking, it is important to mention that L2 learners did not complete the explicit and implicit tasks with the same degree of accuracy. Whereas all participants completed the UGJT with high accuracy, only the French advanced learners were able to show sensitivity to gender discord in the implicit task. However, as far as linear distance is concerned, results cannot define it as a potential source of errors.

The ensuing prediction for the final research question, which examined whether L1 properties and proficiency level influence the detection of errors and the learners' performance as distance increases, was partially supported. On one hand, if we only consider the influence of L1 properties and proficiency level, results indicate that these two between-subjects variables influence the acquisition of gender agreement. On the other hand, in regards to linear distance, it did not make a difference.

To conclude, this study suggests that linear distance is not a potential source of errors in the acquisition of gender agreement. Potentially, this study may encourage future research, which favours the use of syntactic distance as opposed to linear distance. It should also be noted that L1 properties and proficiency level play a deterministic role in the acquisition of gender agreement. This being said, these two between-subjects variables should be included as possible interactions with syntactic distance for future research. 


\section{Acknowledgements}

We thank all the students who participated in our experiments, as well as Sara Downs from the University of Quebec in Trois-Rivieres for providing language help and proof reading the article.

\section{Funding}

This research did not receive any specific grant from funding agencies in the public, commercial, or not-for-profit sectors.

\section{References}

Bañón, J. A., Fiorentino, R., \& Gabriele, A. (2014). Morphosyntactic processing in advanced second language (L2) learners: An event-related potential investigation of the effects of L1-L2 similarity and structural distance. Second Language Research, 30(3), 275-306. doi: https://doi.org/10.1177/0267658313515671.

Bond, K., Gabriele, A., Fiorentino, R., \& Bañón, J. A. (2011). Individual differences and the role of the L1 in L2 processing: an ERP investigation. In J. Herschensohn \& D. Tanner (Eds), 11th Generative Approaches to Second Language Acquisition Conference (pp. 17-29). Seattle, USA: University of Washington.

Bosque, I., \& Demonte, V. (1999). Gramática descriptiva de la lengua española: Entre la oración y el discurso, vol. 2. [Descriptive grammar of the Spanish language: In between sentence and discourse]. Madrid, Spain: Espasa Calpe, S.A.

Corbett, G. (1991). Gender. Cambridge, Great Britain: Cambridge University Press.

Erlam, R. (2006). Elicited imitation as a measure of L2 implicit knowledge: An empirical validation study. Applied Linguistics, 27(3), 464-491. doi: https://doi.org/10.1093/applin/amloo1.

Foote, R. (2011). Integrated knowledge of agreement in early and late English-Spanish bilinguals. Applied Psycholinguistics, 32(1), 187-220. doi: https://doi.org/10.1017/S0142716410000342.

Foucart, A. \& Frenck-Mestre, C. (2011). Grammatical gender processing in L2: Electrophysiological evidence of the effect of L1-L2 syntactic similarity. Bilingualism: Language and Cognition, 14(3), 37999. doi: https://doi.org/10.1017/S136672891000012X.

Gabriele A, Fiorentino R., \& Bañón J. A. (2013) Examining second language development using eventrelated potentials: a cross-sectional study on the processing of gender and number agreement. Linguistic Approaches to Bilingualism, 3(2), 213-232.

doi: http://dx.doi.org/10.1075/lab.3.2.04gab.

Godfroid, A., Loewen, S., Jung, S., Park, J., Gass, S., \& Ellis, R. (2015). Timed and untimed grammaticality judgments measure distinct types of knowledge: Evidence from eye- movement patterns. Studies in Second Language Acquisition, 37(2), 269-297. doi: https://doi.org/10.1017/So272263114000850.

Grüter, T., Lew-Williams, C., \& Fernald, A. (2012). Grammatical gender in L2: A production or a real-time processing problem?. Second Language Research, 28(2), 191-215. doi: https://doi.org/10.1177/0267658312437990.

Instituto Cervantes (2006). Plan curricular del Instituto Cervantes: Niveles de referencia para el español: A1/A2 [Cervantes Institute Curriculum Plan: Benchmarks for Spanish A1/A2]. Madrid, Spain: Biblioteca Nueva. 
Judy, T., Guijarro-Fuentes, P., \& Rothman, J. (2008). Adult accessibility to L2 representational features: Evidence from the Spanish DP. In M. Bowles, R. Foote, S. Perpiñán \& R. Bhatt (Eds): Selected proceedings of Second Language Research Forum (pp. 1-21). Somerville, USA: Proceedings Project.

Keating, G.D. (2009). Sensitivity to violations of gender agreement in native and non-native Spanish: An eye-movement investigation. Language Learning, 53(3), 503-535. doi: https://doi.org/10.1111/j.1467-9922.2009.00516.x.

Lago, S., \& Felser, C. (2018). Agreement attraction in native and non-native speakers of German. Applied Psycholinguistics, First View, 1-29. doi: https://doi.org/10.1017/S0142716417000601.

Lew-Williams C \& Fernald A (2010) Real-time processing of gender-marked articles by native and nonnative Spanish speakers. Journal of Memory and Language, 63(4), 447-64. doi: https://doi.org/10.1016/j.jml.2010.07.003.

Lichtman, K. (2009). Acquisition of attributive and predicate adjective agreement in L2 Spanish. In Melissa Bowles et al. (Eds), 1oth Generative Approaches to Second Language Acquisition Conference (pp. 231-247). Somerville, USA: Cascadilla Proceedings Project.

Montrul, S., Foote, R., \& Perpiñán, S. (2008). Gender agreement in adult second language learners and Spanish heritage speakers: The effects of age and context of acquisition. Language Learning, 58(3), 503-553. doi: https://doi.org/10.1111/j.1467-9922.2008.00449.x.

Montrul, S., de la Fuente, I., Davidson, J., \& Foote, R. (2013). The role of experience in the acquisition and production of diminutives and gender in Spanish: Evidence from L2 learners and heritage speakers. Second Language Research, 29(1), 87-118.

doi: https://doi.org/10.1177/0267658312458268.

Morales, L., Paolieri, D., Dussias, P. E., Valdés Kroff, J. R., Gerfen, C., \& Bajo, M. T. (2016). The gender congruency effect during bilingual spoken-word recognition. Bilingualism: Language and Cognition, 19(2), 294-310. doi: https://doi.org/10.1017/S1366728915000176.

Paquet, P.-L. (2018). Influence of L1 properties and proficiency on the acquisition of gender agreement. Journal of Language \& Education, 4(1), 92-104. doi: https://doi.org/https://doi.org/10.17323/2411-7390-2018-4-1-92-104.

Real Academia Española (2010). Nueva gramática de la lengua española manual [New handbook of the Spanish grammar]. Barcelona, Spain: Espasa.

Roberts, L., \& Siyanova-Chanturia, A. (2013). Using eye-tracking to investigate topics in L2 acquisition and L2 processing. Studies in Second Language Acquisition, 35(2), 213-235. doi: https://doi.org/10.1017/S0272263112000861.

Sagarra, N., \& Herschensohn, J. (2010). Proficiency and animacy effects on L2 gender agreement processes during comprehension. Language Learning, 61(1), 80-116.

doi: https://doi.org/10.1111/j.1467-9922.2010.00588.x.

Sagarra, N., \& Herschensohn, J. (2011). Asymmetries in gender and number agreement processing in late bilinguals. In: L.A. Ortiz-López (Ed.), 13th Hispanic Linguistics Symposium (pp. 169-177). Somerville, USA: Cascadilla Proceedings Project.

Tokowicz, N., \& MacWhinney, B. (2005). Implicit and explicit measures of sensitivity to violations in second language grammar: An event-related potential investigation. Studies in Second Language Acquisition, 27(2), 173-204. doi: https://doi.org/10.1017/So272263105050102.

Vafaee, P., Suzuki, Y., \& Kachisnke, I. (2017). Validating grammaticality judgment tests: Evidence from two new psycholinguistic measures. Studies in Second Language Acquisition, 39(1), 59-95. doi: https://doi.org/10.1017/S0272263116000097.

Zhang, R. (2015). Investigating linguistic knowledge of a second language and its relationship to general language proficiency and individual learner differences in an EFL context (Published doctoral dissertation, University of Auckland, Auckland, New-Zealand). 
P.-L. Paquet - Linear Distance: A Multi-Tiered Methodology in the Acquisition of Gender Agreement

C O A $\mathbf{s}$ 